
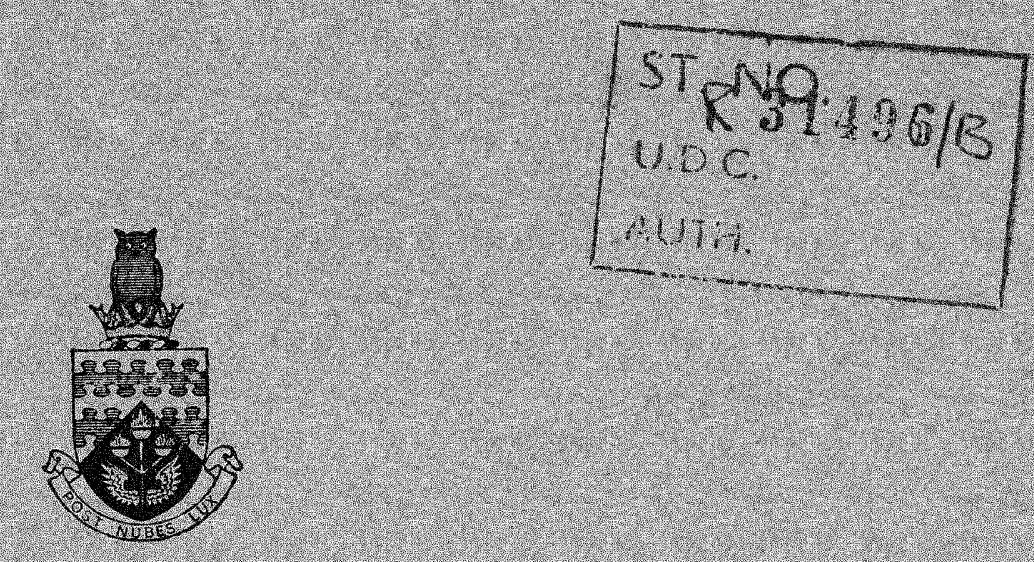

\title{
THE COLLEGE OF AERONAUTICS
}

\section{CRANFIELD}

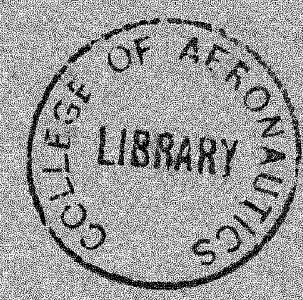

ON THE FLOW ALONG SWEPT LEADING EDGES

$$
\text { by }
$$

M. Gaster 
THE COIIEGE OF AERONAUTICS

DEPARTMEII OF AERODYNAMICS

On the flow along swept leading edges

- by -

M. Gaster, Ph.D., B.Sc., A.I.M.

\section{SUM M A R Y}

Flight tests on the Handley Page suction wing showed that turbulence, generated at the wing root, can propagate along the leading edge and cause the whole flow to be turbulent. The flow on the attachment line of a swept wing was studied in a low speed wind tunnel with particular reference to the problem of turbulent contamination.

The critical Rejnolds number, $R \theta_{I}$, of the attachment line boundary layer for the spanwise spread of turbulence was found to be about 100 for sweep angles in the range $40^{\circ}-60^{\circ}$. A device was developed to act as a barrier to the turbulent root flow so that a clean laminar flow could exist cutboard. This device was shown to be effective up to an $R \theta$ of at least 170. With the aid of this bump experiments were possible on a laminar boundary layer at Reynolds numbers above the lower critical value. A spark was used to introduce spots of turbulence into the attachment line boundary layer and the propagation speeds of the leading and trailing edges were measured. The spots expanded, the leading edge moving faster than the trailing edge, at high Reynolds numbers, and contracted at low values.

The behaviour of Tollmien-Schlichting waves was also investigated by exciting the flow with sound emanating from a small hole on the attachment line. Measurements of the perturbation phase and amplitude were made downstream of the source and although accurate values of vave length and propagation speed could be found, no difficulties vere experienced in evaluating the amplification ratio. Nevertheless, all small disturbances decayed at a sufficient distance frce the source hole up to the highest Reynolds number tested of 170 .

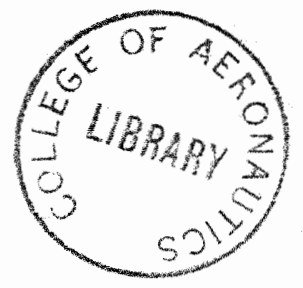


Page No:

\section{Summary}

1. Introduction : I

2. Flight observations I

3. Wind tunnel tests 3

3.I The decay of turbulence behind trip wires 3

3.2 A critical roughness criterion 4

3.3 Velocity profiles behind roughness elements 5

3.4 Preventing contamination with a 'bump' 6

3.5 Propagation of turbulent spots 7

3.6 Small amplitude disturbances 8

4. Conclusions 11

References 11 


\section{Introduction}

Hight tests on the Handley Page laminar flow suction wing were frustrated at high Reynolds numbers because the flow became turbulent on the leading edge attachment line. The trouble appeared to arise through turbulence, generated at the wing-fence junction, creating a turbulent boundary layer which swept along the attachment line when the speed was above some critical level. The series of wind tunnel tests described in this paper were undertaken to obtain a better understanding of the problem. It was also intended to find some method of containing the attachment line turbulent boundary layer within the root region of the wing so that the tests on the laminar flow wing could be extended to higher speeds. Pfenninge ${ }^{\prime}$ s group working on the $X-2 I$ project encountered similar troukles and also resorted to tunnel tests (Pfenninger 1964).

\section{Flight Observations}

The suction wing was mounted vertically on the fuselage of a Lancaster bomber (see fig. 1) and flown at speeds up to $200 \mathrm{knots,} \mathrm{enabling} \mathrm{higher}$ Reynolds numbers to be achieved than was possible in any existing wind tunnel in this country.

Although this technique has been successfully employed on unsucked wings (Burrows 1956), the investigation of a laminar flow surface, which is difficult enough in a wind tunnel, presents considerably greater problems of instrumentation. Burrows used the velocity profiles which were obtained with pitot-combs to find the transition position, but in the present case, where the boundary layers were extremely thin, this technique could not be used and special insirumentation had to be developed to reveal the state of the flow. A type of hot-film gauge, which could be simply held on the wing surface with adhesive tape, was developed (Gaster 1965a) for detecting transition in flight. These gauges proved particularly useful on the attachment line where the boundary layer was at its thinnest. The geuges were made from Pyrex microscope slides which were cut into strips, ground and polished to the required shape before having a thin platinum film fired on the tip. A rinished gauge is shown in fig. 2 . These instruments operate in the same manner as hot-wires, but are far more robust and are therefore more suitakle for flight work. The gauges were run in the constant current mode, the current being derived from a 12 volt accumulator and series resistor. Any turbulerce in the fllow over the gauge produces fluctuations in film temperature which are reflected in the voltage across the gauge. The flight observer can thus check whether the flow is laminar or turbulent by examining this signal on the oscilloscope carried in the aircraft. The gauges were only used to indicate the state of the flow and there was sufficient frequency response and sensitivity for this without the need for the special compensated amplifiers normally used for measurement purposes.

Figure 3 shows typical signals from a gauge on the leading edge. At the lowest speed the signal was clean and the flow was clearly laminar, but 
as the speed was increased above some 'critical' value isolated pulses occurred and finally, at even greater speeds, the signal became fully turbulent. To demonstrate that these 'critical' speeds would correlate on the basis of a leading edge radius Reynolds number, a flight was planned with test runs at three altitudes, 22,000, 10,000 and 3,000 ft. so that the viscosity could be varied. The results from this flight fully confirmed the idea of a critical leading edge Reynolds number (fig. 4), but a more useful parameter is given by the Reynolds number of the boundary layer along the attachment line. This Reynolds number, in terms of the momentum thiciness, has also been used by Pfenninger (1963 and 1964) and by Gregory (1964).

The momentum thickness, $\theta$, of the boundary layer along the attachment line is given by

$$
\theta=.4044 \sqrt{\frac{d q}{d s}}
$$

where $\frac{d q}{d s}$ is the velocity gradient of the componert of the potential flow normal to the leading edge, and $R \theta$ is given by

$$
\frac{U_{\infty} \cdot \theta \cdot \operatorname{Sin} \phi}{v}
$$

where $\phi$ is the angle of sweep and $U_{\infty}$ is the freestream velocity.

As the boundary layer on the attachment line is in general very thin it is usual to calculate the value of the momentum thickness from the potential flow around the nose of the aerofoil. Equation (I) applies only to the case of laminar flow and values of $R \theta$ calculated on this basis are clearly incorrect if the flow is turbulent. However, since this parameter is fairly simple to evaluate it has been used quite indiscriminantly for both laminar and turbulent flows, and provided one takes note that it may not equal the true value of $R \theta$ no difficulty arises. This parameter will be used in the present paper for all types of flow and it will be denoted by $R \theta_{I}$. In the flight experinents a critical value of $R \theta_{I}$ for the start of transition was found to be 88. Transition was complete at an $R \theta_{L}$ of about 96 .

Wind tunnel tests confirmed that the trouble was one of turbulent contamination spreading out from the root, and not natural transition of the attachment line flow which at one time had seemed a possibility. In fact contamination of the outboard region of a swept wing from a large roughness element had previously been reported by Gregory (1960), and even earlier by Gray (1952), who described surface indicator observations from flight trials. It seems strange that the possibility of this trouble had not been anticipated either on the Handley Page test wing or on the complete $X-21$ aircraft built by Northrop. Gray showed that turbulent flow existed close to the leading edge of swept wings and he attempted to correlate 
transition speed with leading edge radius. In some of these flight experiments a fine pattern of striations often appeared in the naphthalene sublimation photographs of the transition region near the leading edge. Gregory and Walker (1952), using the china-clay technique, found a similar effect in the wind tunnel on a swept Griffiths section. The threedimensional instability which was assumed to cause this pattern was explained in mathematical terms by Owen and RandalI ( 1952 and 1953), and Stuart (1953). A beautiful demonstration of this type of instability leading to striation patterns was given by the transition of the boundary layer on a rotating disc. The boundary layer on a rotating disc exhibits a similar three-dimensional characteristic to that of the flow near the leading edge of a swept wing (Gregory, stuart and Walker, 1955). The use of suction around the nose of a swept aerofoil not only things the boundary layer, but also reduces this strong de-stabilising crossflow profile so that by careful design of the suction distribution premature transition from three-dimensional instability cen be prevented. Although Gray observed turbulent contaminatior spreading outboard from a trip wire wrapped round the leading edge, and in fact suggested that this could be one cause for the breakdown of laminar flow on swept wings, it appears that once the three-dimensional instability had been identified there was no incentive at that time for any further investigation of the problem.

\section{Wind TunneI Tests}

The model used in these tests was built up with ribs mounted on a central spar and covered with a thin plyrood skin. The dimensions and section of the wing are shown in fig. 5 . The model was swept forward so that the upstream attachment line boundary layer near the tip, where the leading edge radius was smallest, would have a substantially Lower Reynolds numbor than that at the root. In this way it was possible to have the tip boundary layer below the critical Reynolds number, so that any turbulence created at the upstream stagnation point decayed. A laminar layer could thus be created above its ' lower critical speed' over the root region so that measurements could be made in this regime.

As these experiments were only concerned with the flow on or near the attachment line a simple circular leading edge was chosen, the remainder of the teardrop section being added to prevent an oscillatory wake forming which might upset the attachment line flow. The natural plywood was not considered to have a sufficiently good surface for a laminar flow experiment and a sheet of 0.005 ins. Melinex was wrapped around the leading edge to present a smooth finish to the oncoming flow.

\section{I The decay of turbulence behind trip wires}

In the initial tunnel tests the state of the boundary layer was determined with a surface total-head probe coupled to a stethoscope. A loud roaring sound could be heard through the stethoscope when the flow was turbulent, while only a low hiss was generated by a purely laminar boundary layer. 
the transition zone it was possible to hear isolated turbulent spots passing the total head probe.

The first series of wind tunnel tests were concerned with the distance necessary for the decay of turbulence introduced into the boundary layer by trip wires wrapped round the leading edge. Various sizes of trip wire were attached to the leading edge ahead of the surface total head probe and the highest tunnel speed at wich the flow remained laminar was obtained. The results of these tests, (fig. 6), obtained with the wing set at $45^{\circ}$ sweep, show how the decay length varies with speed for the different trip diameters. These critical decay speeds lie, as far as can be judged by listening to the stethoscope, about halfway between the fuliy turbulent and clean laminar signals. Although the precise position in the transition band can not be easily defined, one operator was able to achieve a reasonable degree of consistericy. In order to obtain the values of $R \theta_{I}$ in fig. 6 , it was assumed that the flow over the front portion of this model was approximately that on a yawed circular cylinder. Measurements of the attachment line. velocity profile, to be discussed later, have shown that this is a justified ?ssumption.

At large distances from the trip all the curves in fig. 6 for the various wires tend to a limiting value of $135 \mathrm{ft} / \mathrm{sec}$. This is the critical speed above which any turbulence, once introduced into a laminar flow, will propagate along the attachment line. As this particular test model was tapered, the value of $\theta$ varied along the span and it was not at all obvious which was the most appropriate value of $R \theta_{L}$ to use for the correlation of data. It was generally most convenient to use the value calculated on the basis of local conditions near the surface probe or hot-film detector, and this would lead to value of $R \theta_{I}$ being too high for the wind tumnel model and too small for the flight work where the wing tapers down towards the tip. The critical value of $R \theta_{I}$ found on the tunnel model was 100 , while the flight tes ting gave 88. Some intermediate value of about 95 is probably therefore most appropriate to the case of an untapered wing.

These decay tests were repeated for other angles of sweep and the critical values of $R \theta_{I}$ for the propagation along the whole length of leading edge are plotted in fig. 7. Clearly this boundary layer Reynolds number, $R \theta_{I}$, is a proper parameter for defining transition speed.

\subsection{A critical roughness criterion}

By extending the experiments on decay behind a wire to wires of small diameter it was possible to determine a critical roughness height for round elements. Fig. 8 shows the free stream velocity plotted against trip diameter for various decay distances. The curves tend to a single line in the limit of very rapid decay and it is convenient to define the critical height in this way. From this plot the critical trip wire size is shown to be inversely proportional to the tunnel velocity raised to the power three-quarters. In terms of $R \theta_{I}$, 


$$
\left(\frac{\mathrm{dU}}{v}\right)_{\text {crit. }}=47 \cdot R \theta_{2}^{\frac{1}{2}}
$$

where $d$ is the trip wire diameter and subscript s refers to the component of velocity along the attachment line. Garner (1948) showed how the data given by Fage (1943) for the critical size of roughness elements on a flat plate could be correlated by the relation

$$
\left(\frac{d U}{v}\right)_{\text {int }}=36 \mathrm{R}_{x}^{1 / 4}
$$

This may be written $\left(\frac{d U_{S}}{V}\right)_{n t}=44 \theta^{\frac{1}{2}}$, which is in excellent agreement with values found on the leading edge. Gregory (1964), who has carried out similar experiments on swept leading edge flows, has also obtained a critical wire size consistent with the above relation.

\subsection{Velocity profiles behind roughness elements}

A traversing hot-wire was used to measure the velocity profiles of the aitachinent line boundary layer flowing along the leading edge. The probe was coupled to a micrometer head which could only be moved from inside the tunnel. This restricted the maximum speed of the tests to $80 \mathrm{ft} / \mathrm{sec}$, as it was not easy to enter the tunnel when running above this speed and it was considered too time-consuming to slow down the tunnel between readings when running faster. The velocity profiles were measured at various stations downstream of a $3 / 16 \mathrm{in}$. diameter trip wire at speeds of 40,60 and $80 \mathrm{ft} / \mathrm{sec}$. With the wing swept at $45^{\circ}$. The flow just downstresm of the trip is typical of a turbulent boundary layer near a reattachmert point. The profiles then revert back to the thin laminar shape. The results for the $40 \mathrm{ft} / \mathrm{sec}$. tests are shown in fig. 9 as contours of constant velocity, as measured by the hot-wire anemometer. The profiles further downstream are compared in $f i g .10 \mathrm{with}$ the theoretical laminar profile calculated on the assumption that the potential flow was the same as that on a yawed circular cylinder of the same leading edge radius. As one might expect, the velocity profiles appear to become fully laminar most quickly for the low speed case. The distance from the wire to the station where laminar flow was indicated by the stethoscope was a little further downstream than one migh.t expect from the shape of the vebocity profiles. A further set of profiles taken with the wing swept at 60 with a $1 / 16$ in. trip 2 ft. upstream of the wire is shown in figure 1工. A gradual change from a laminar to a fuller turbulent profile occurred as the Reynolds number increased, but at the critical valuc of about 100, when the stethoscope indicated the passage of turbulent spots, the profile still remained close to the laminar shape. The measured values of $R \theta$ compare well with those calculated for laminar flow for the 40 and $60 \mathrm{ft} / \mathrm{sec}$. profiles, but at higher 
speeds the profile shape diverges and the actual measured momentum thickness becomes very much greater than the laminar value.

\subsection{Preventing contamination with a 'bump:}

When all trip wires were removed from the leading edge a clean laminar flow without spots of turbulence could only be achieved near the root at speeds below $180 \mathrm{ft} / \mathrm{sec}$. At this speed the critical value of $R \theta_{I}$ had been reached at the tip of the model and the trouble presumably arose through a rather rough fairing there. To enable the present series of experiments to be extended to higher values of $R \theta_{I}$, and the tests on the Handley Page suction wing to be completed, some device for preventing contamination was required. Pfenninger employed leading edge extensions which locally sharpened the aerofoil sertion and reduced the value of $\theta$ below the critical by thinning the boundary layer on the attachment line. He also used fences to prevent the turbulent flow sweeping along the leading edge, but he found that it was necessary to apply suction at the joint with the wing to remove the boundary layer which formed on the fence. Boundary layer control of the attachment line flow by sucking through transverse slits was also used with success on wind tunnel models and has now been incorporated on the $X-2 l$.

A local reduction of the leading edge radius restricts the incidence range of the section, while the other systems for preventing contamination require the added complication of suction. A further device was the refore developed in an attempt to overame these disadvantages (Gaster, 1965b). Figure 12 shows this 'bump' fitted on the wind tunnel. model. The steeply rising leading edge is intended to create a stagnation point so that the turbulent attachment line boundary layer is brought to a halt and is prevented from flowing over the remainder of the wing. The steep escarpment has to be rounded off and smoothly faired into the wing to prevent any unduly large adverse pressure gradient acting on the newly formed laminar boundary layer and causing transition. Initial tests with a plasticine bump on the wind tunnel model swept at $45^{\circ}$ gave an immediate improvement in the maximum speed that could be reached without any spots of turbulence appearing downstream. However, the maximum tunnel speed could not be reached with the boundary layer in a wholly laminar state until the plasticine surface of the bump had been carefully smoothed down and all grit and other roughness removed. A plaster cast of the plasticine shape was taken so that a more permanent polyester reproduction could be made. This moulding was bonded to the leading edge of the wind tunnel model and the trailing edge of the bump was smoothly blended to the surface with filler. The surfaces were then rubbed down with fine wet silicon carbide paper to provide the necessary finish. With this improved bump laminar flow was achieved up to the top speed of the tunnel giving an ROI of 141 . Surface flow patterns (fig. 13), which were obtained with lamp-blacis and paraffin, showed that a stagnation point was formed on the forward facing step of the bump. A number of copper tubes were moulded into the bump so that the pressure distribution along the attachment Iine could be measured at various sweep angles. The measured

* British Patent Application NC. 51305/64. 
pressure distributions confirmed the existence at $45^{\circ}$ sweep of a stagnation where the surface flow patterns had indicated, but it was found that when the leading edge sweep angle approached $60^{\circ}$ no stagnation arose and the device failed to prevent contamination. A plasticine extension was fitted to the bump to steepen the forward facing step in order to re-establish a stagnation region there. Although the surface flow technique could not be use $z$ on the soft plasticine surface to reveal the presence of a stagnation, fully laminar flow was maintained up to an $R \theta_{I}$ of 170 downstream of this modified bump.

A similar bump, which has been fitted on the Handley Page suction wing to prevent turbulent contamination, has proved successful in both wind tunnel and flight tests, enabling the laminarized slitted wing surface to be tested at the designed Reynolds number. Wind tunnel tests in the $13^{1} \times 9^{1}$ at R.A.E. Bedford showed that the bump had an incidence tolerance of at least $\pm 2^{\circ}$ at $R \theta_{I}$ values of 116 . Flight tests have shown that the incidence tolerance is about $\pm 2 \frac{1}{2}^{\circ}$ and the flow has been maintained in a laminar state up to 225 knots $\left(R \theta_{I}=130\right)$ the maximum speed of the aircraft. The difference between wind tunnel and flight tests presumably arises because the low turbulence levels encountered in flight can not be achieved in the tunnel when running near its maximum speed.

\subsection{Propagation of turbulent spots}

In the experiments on the natural decay of turbulence along the attachment line $\left(R \theta_{I}\right.$ below the critical value), the turbulent boundary layer was found to break up into separate patches of turbulence. To find how these turbulent regions expand (or contract) as they travel along the leading edge, turbulent pulses were artificially induced by a spark. This method hai been previously used by Schubauer and Klebanof (1955) for investigating the growth and shape of turbulent spots on a flat plate. Using a bump to obtain a clean laminar flow it was possible to study the behaviour of these artificially generated spots over a wide range of Reynolds numbers from 95, well below the critical, to 170 , which is considerably above.

The high voltage spark, generated by an ignition coil, was made to jump $3 / 8$ inch across the attachment Iine between a pair of copper electrodes which were glued to the wing surface downstream of the bump. The points of the electrodes were sufficiently far from the attachment line for the wakes to be always off the attachment line. A hot-film gauge was taped on the leading edge downstream of the spark so that any spots of turbulence from the spark could be observed on an oscilloscope. The spark unit was fired by a short duration electrical pulse which was also used to trigger the sweep on the oscilloscope so that the complete time history of the gauge signal was displayed on the screen from the instant of firing the spark to the passage of the spot. By using a suitable delay time on the sweep trigger pulse and increasing the sweep speed it was possible to expand the portion of the sweep containing the turbulent spot. Typical oscilloscope records are shown in fig. 14. As the wind tunnel tests were made using a relativeiy large 
model at low speed typical frequencies arising in the turbulence were considerably lower (by a factor of about 10) than those arising on the wing used for the flight work.

A continuous train of pulses was used to generate a series of turbulent spots so that a steady display of the gauge signal was shown on the oscilloscope screen. Although the details of the turbulence varied for each spot, the leading and trailing edges occurred at almost the same position on the screen, and a mean position could easily be estimated by observing the screen for a minute or so. It was found convenient to reduce the low frequency response of the signal by introducing a simple resistance-capacity filter in order to remore the 'tail' that occurred at the trailing edge (see fig. 14). The trailing edge was taken to be at the point where the signal crossed the axis. This choice seems somewhat arbitrary, but at least it introduces consistency into the measurements. The time taken for the leading and trailing edges to reach a gauge stationed at various distances along the attachment $I$ ne was obtained for various tumel speeds. This information has been reduced to the form shown in fig. 15, where the velocities of the edges of these spots are plotted against the momentum thickness Reynolds number $R^{\mathrm{L}}{ }_{\mathrm{L}}$.

Both sets of data are similar and show that the velocities of the leading and trailing edges of the turbulent spots may be different. This difference in the two velocities depends on the value of the Reynolds number. For large Reynolds numbers, $R \theta_{\mathrm{I}}$ greater than 113 , the leading edge moves faster than the trailing edge so that the pulses expand, while below this critical speed they contract. At the critical Reynolas number, $R \theta_{\Gamma}=113$, pulses of turbulence neither expand nor contract and the length of the turbulent regions remain constant as they propagate along the attechment line. Below the critical Reynolds number we can expect spots to contract and eventually disappear on a long enough leading edge, but we find in practice that the critical Reynolds number for the ultimate decay of turbulence behind trip wires is about 100. The present tests have been concerned with relatively long bursts of turbulence, where the leading and trailing edges can be considered independent of one another, while in the final stages of the decay process behind trip wires the pulses are narrow, and it is not at all obvious that the rate of contraction will be the same in the two cases. More experiments need to be curried out on a model. having a longer length of constant radius leading edge to shed more light on this apparent anomaly.

\subsection{Small amplitude disturbances}

When turbulent contamination is prevented, by means of a fence or bump, the attachment line boundary layer can be maintained in a laminar state well above the lower critical value for the growth of spots. However, there must be some upper Reynolds number limit beyond which small disturbances, originating from tunnel turbulence, sound, etc., grow and eventually cause transition. The linear theory of hydrodynamics stability (Lin, 1955) 
considers the growth and propagation of small periodic disturbances, and this theory has been shown to explain the initial stages in the transition processes of boundary layers, jets, and wakes, provided the external stimuli in the form of wall roughness and free stream turbulence are sufficiently small for the phenomenon to be treated as a linear one. If the rlow along the leading edge follows a similar pattern of behaviour we can expect travelline waves to arise from external excitation. These waves would grow spatially as they propagate along the attachment line when the Reynolds number is greater than some critical value, and decay when it is below this upper critical level. On a leading edge of constant radius the attachment line boundary layer thickness Reynolds number is constant and the ampifification or damping ratio will be the sane over the whole length of the span. Thus slightly above the critical speed for neutral stability we can expect small disturbances at the root to frow outboard and, if the leading edge is sufficiently long, cause breakdown to turbulent flow near the tip. As the speed is increased and the arplification ratios get larger this transition point will move closer to the root. Provided the value of $R \theta_{I}$ is kept below the critical for amplified modes to arise laminar flow on the attachment line should be maintained along the whole span, however long. The value of this upper critical Reynolds number is uncertain at the present time; experiments have not been performed at sufficiently high Reynolds numbers to reveal this and the theoretical calculations based on stability theory, for the complex three-dimensional flow near the attachment, have not been made. By considering the velocity profile along the attachnent line and treating the problem as a twodimensional ore, a value of about 200 for $R \theta I$ is obtained, although Pfenninger (1964) has suggested that the three-dimensional nature of the flow on the leading edge will stretch the disturbance vorticity and so reduce the stability of the system. By comparing the stability of the Plow at the stagnation point on a sphere with that of the two-dimensional flow having the same profile he has deduced that a value of about 120 is appropriate for the case of the attachment line on a swept wing. The following experiments were carried out in order to evaluate this Reynolds number.

Schubauer and Skramstad (1947) used a thin flat vibrating ribbon near the surface of a flat plate to excite travelling waves in a boundary layer so that they could compare the wave lengths, rates of growth, etc., with those waves which had been theoretically predicted by Schlicting (1933), Tollmien (1929) and others. This technique was not suitable for highly curved surfaces, such as the present leading edge, and a different approach had to be tried. Schubauer also tried to generate waves with a small earphone buried beneath the plate surface, the pressure pulses exciting the flow via a small hole through the plate to the diaphragm chamber. Although they were able to generate travelling waves on their plate, the single hole produced a three dimensional pattern which was not suitable for direct comparison with the two-dimensional theory. On the attachment line, where the instability will be three-dimensional anyway, the buried earphone set-up seemed ideal. Figure 16 shows the arrangement employed on the swept leading edge model. The earphone was fed with sine waves of various frequencies and the 
oscillations in the Ilow were detected with a hot-filn gauge on the attachment line downstream of the hole. The film was able to pick up oscillations over a band of frequencies and it was found that this preferred band changed with tunnel speed in the vay one might expect for travelling instability waves. The hot-film gauge vas attached to a micrometer mechanism so that it could be finely traversed for one inch behind the hole. The hot-film signals were passed through a tuneable filter, which was centered on the frequency being fed to the earphone, and displayed as a Iissajou figure on the oscilloscope. By moving the gauge closer or further from the hole the pattem was changed showing variation in phase with distance, $\mathrm{I} i \mathrm{c} .17$. The actual measurement of phase angle was azcomplished more readily by comparing the two signals on a double beam oscilioscope (sce figure 18). Firure 19 shows results of a series of such observations taken at a tunnel speed of $100 \mathrm{ft} / \mathrm{sec}$. These straight lines show quite clearly that the oscillations are travelling waves propagating downstream, and from their slope one can evaluate the propagation speed and wave-number. The data collected from these plots, shown in table $I$, is consistent with values predicted theoretically for Tollmein-Schlicting waves. The amplitude of these forced oscillations is plotted against distance from the source hole in rigure 20 , but the se curves are not exponential and one is not able to evaluate damping ratios. This difficulty arises presumably because the wave pattern is not a single wave progressing along the attachment Iine. Nevertheless, it was quite clear that all disturbances did decay, even up to $R O \mathrm{I}$ values of 170 , and that the upper critical Reynolds number lay outside the range of this experiment. It was hoped that traverses taken further from the source, where one might expect the disturbance to behave more lire a two-dimensional wave, would enable rough estimates of the decay to be made so that the critical Reynolds number could be founa by extrapolation, but again the strongly three-dimensional nature of the pattern, which was revealed by traversing a film gauge round the surface, prevented this. Using a slot instead of a single hole improved the downstream disturbance pattern, but not sufficiently. It was also found that above a certain critical Reynolds number, of about 100 , small amplitude wavy fluctuations appeared along a narrow region on the attachment line without any artificial input. The erequency of these disturbances was roughly the same as that of the most easily artificially excited waves, and it was difficult to separate out the forced motion from that occurring naturaliy. This phenomenon could not be observed with a hot-wire probe when one was used, and it was subsequently found that the waves vere induced by the presence of the hot-film gauge. This was proven quite conclusively when the hot-wire was mounted just in front of the bevel of the glass gauge and showed similar signals to those given by the film cauge. The gauge presumably distorts and destabilises the oncoming stream so that natural turbulence, or any small oscillations in the boundary layer, grow and provide a large fluctuation at the gauge. This amplifying action must be quite local and the measurements comparing the amplitude at one station with that at another using the same gauge must still be correct. The hot-wire was used in place of the rilm at speeds above an $R \theta_{\mathrm{I}}$ of 100 , but all disturbances were again found to decay. A model vith a larger leading eage radius is therefore 
required to extend the present series of tests up to higher Reynolds numbers.

\section{Conclusions}

The difficulties encountered in carrying out the plight research programme have been shown to arise through the turbulent contamination of the attachment line from the turbulent boundary layex on the root fence. A device for preventing this contamination has been suggested and a model has been made to test it in the wind tunnel where it was shown to be effective. The device has been incorporated on the Handley Page test wing and used in both the tunnel and fight test programes where it has proven satisfactory.

A criticel rouginess height for round wire elements has been established on the leading edge and it has been shown to be almost identical to that given by Garner for experiments on a flat plate. Further work should be done on three-dimensional roughnesses to see how these compare.

Turbulence has been shown to decay to the laminar state below the critical Reynolds number through the difference in speed between the leading and trailing edge of spots of turbulence.

To complete the programme and obtain the eritical Reynolds numbers for small disturbances it is necessary to repeat some of these experiments on a larger model, preferably of constant radius.

\section{References}

1. Burrows, F.M. (1956)

2. Fage, A. (1943)

3. Gaster, M. (1965(a))

4. Gaster, M. (1965(b))
A theoretical and experimental study of the boundary layer flow on a $45^{\circ}$ swept back wing. College of Aeronautics Report No. 109.

The smallest size of spanwise surface corrugation which effects a boundary layer on an aerofoil. $\mathrm{R}$ and $\mathrm{M} 2120$.

The application of hot-film gauges to the detection of transition in flight. College of Aeronautics Report No. 189.

A simple device for preventing contamination on swept leading edges.

J. Roy. Aero. Soc. 69 . 
5. Garner, H.C. (1948)

6. Gray, W.E. (1952)

7. Gregory, N. (1960)

8. Gregory, N. (2964)

9. Gregory, N. and Walker, W.S (1952)

10. Gregory, N., Stuart, J.T. and Walker, W.S. (1955).

II. Iin, C.C. (1955)

12. Owen, P.R. and RandaII, D.G. (1952)

13. Pfenninger, W. (1963)

14. Pfenninger, W. (1964)

15. Schlichting, H. (1933)
See 'Wind turnel technique'

Pankhurst, R.C. and Holder, D.W.

Pitman 1952.

The nature of the boundary layer flow at the nose of a swept wing.

R.A.E.T.M. Aero. 256.

ARC Report 15,021.

Transition and spread of turbulence on a $60^{\circ}$ swept-back wing.

J. Roy. Aero. Soc. 64, 562 .

Laminar flow on a swept leading edge. and progress report.

N.P.I. Aero. Memo. No. 12.

Brief wind tunnel tests on the effect of sweep or laminar Plow.

A.R.C. Report 14,925.

On the stability of three-dimensional boundary layers with application to the flow due to a rotating disc.

Phil. Trans. (A) $243,155$.

'The theory of hydrodynamic stability' Cambridge University Press.

Bouncary layer transition on a swept-back wing.

R.A.T. T.M. Aero. 277.

A.R.C. report 15,022 .

Preliminary note about an experimental verification of the turoulent spanwise contamination on a swept wing. Northrop Norair Memorandum 3850-362, 17th July.

About some flow problems in the leading edge region of swept laminar flow wings. Northrop Norair report BLC-160.

Zur Entolehung der Turbulenz bei der Plattenstromung.

Nachr-Ges. Wiss. Gottingen, Maths- Phys. Klasse, 181-208.

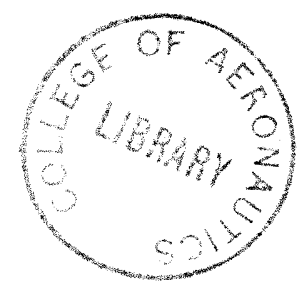


16. Schubauer, G.B. and Skramstad, H.K. (I947)

17. Schubauer, G.B. and Klebanoff, P.S. (1955)

18. Stuart, J.T. (1953)

19. Tollmier, W. (1929)
Laminar boundary layer oscillations and transition on a flat plate.

N.A.C.A. Tech. Rep. No. 909.

Contributions on the mechanism of boundary layer transition.

Proc. Symp. boundary layer efiects. Aerodyn., Nat. Phys. Lab.

The basic theory of the stability of a three-dimensional boundary layer. ARC Report 15,904.

Uber die Enstehung der Turbulenz. Nachr. Ges. Wiss.

Gottingen, Maths-Phys.

Klasse 21-44.

(NACA Tech. Memo. 609). 


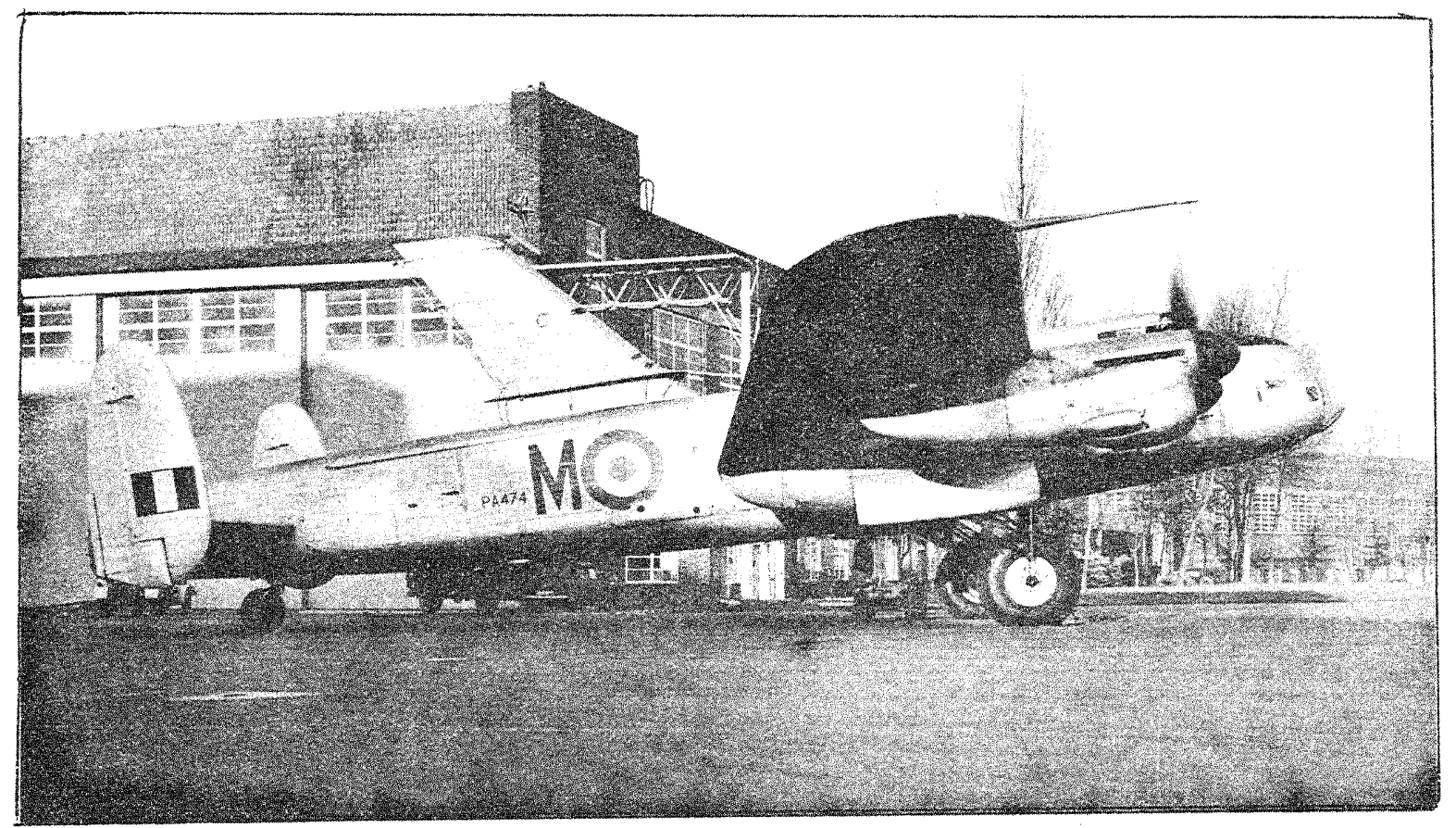

FIG. 1 THE HANDLEY PAGE LAMINAR FLOW WING MOUNTED ON THE LANCASTER

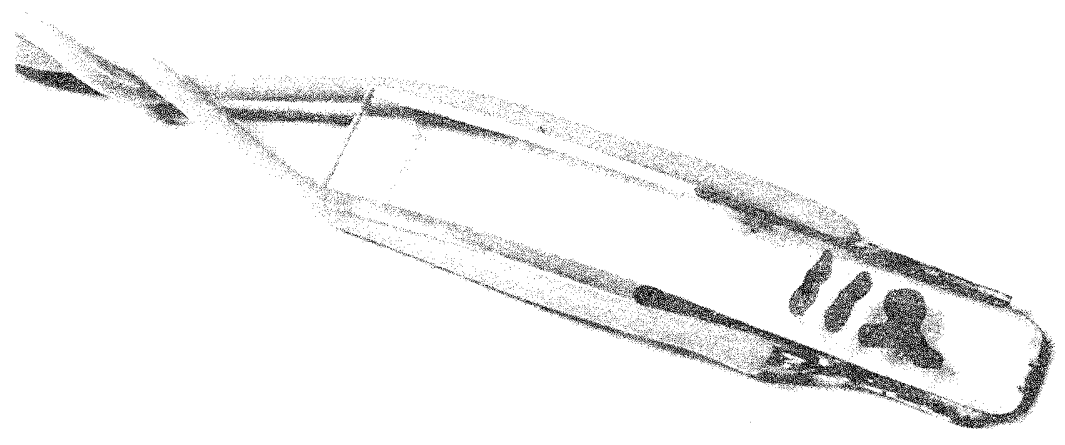

\section{1}

FIG. 2 HOT-FLLM GAUGE USED FOR DETECTION OF TRANSITION 
SPEED INCAEASING

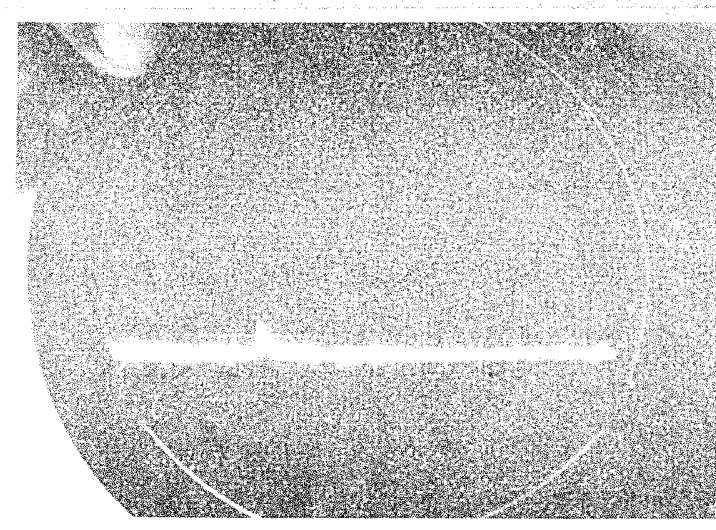

LAMNAR

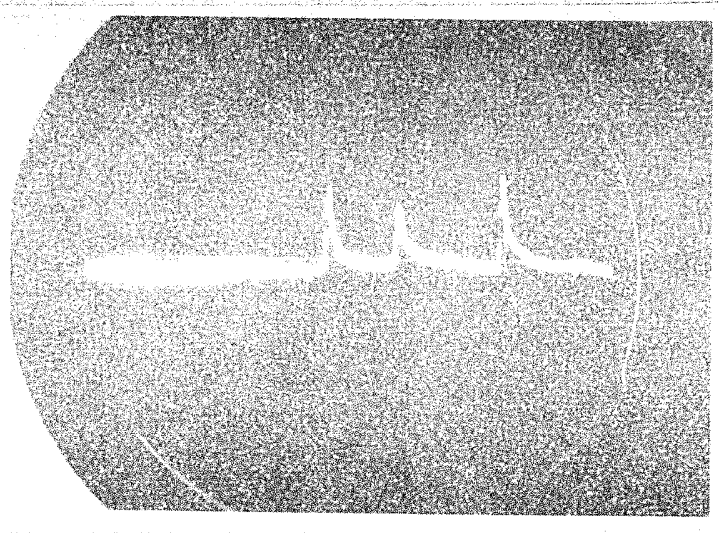

PULSES OF TURBULENCE

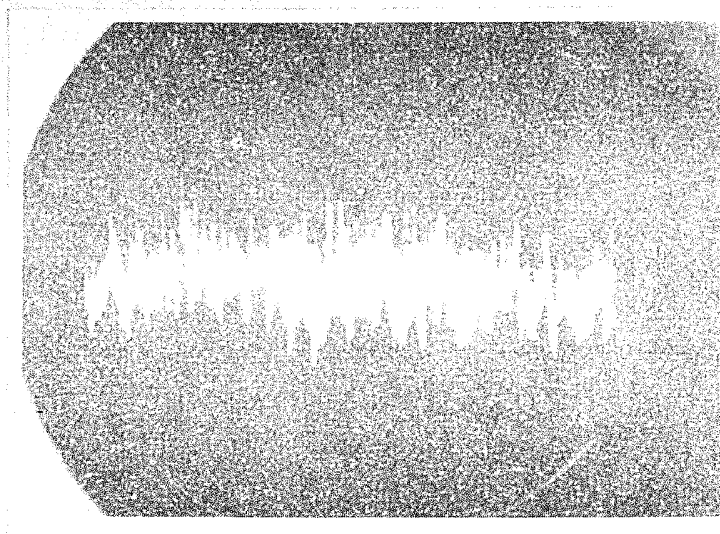

TURBULENT

FIG.3. OSCILLOSCOPE PHOTOGRAPHS OF HOT-FILM SIGNALS OBTANED IN FLIGHT WITH THE GAUGE ON THE ATTACHMENT LINE. 


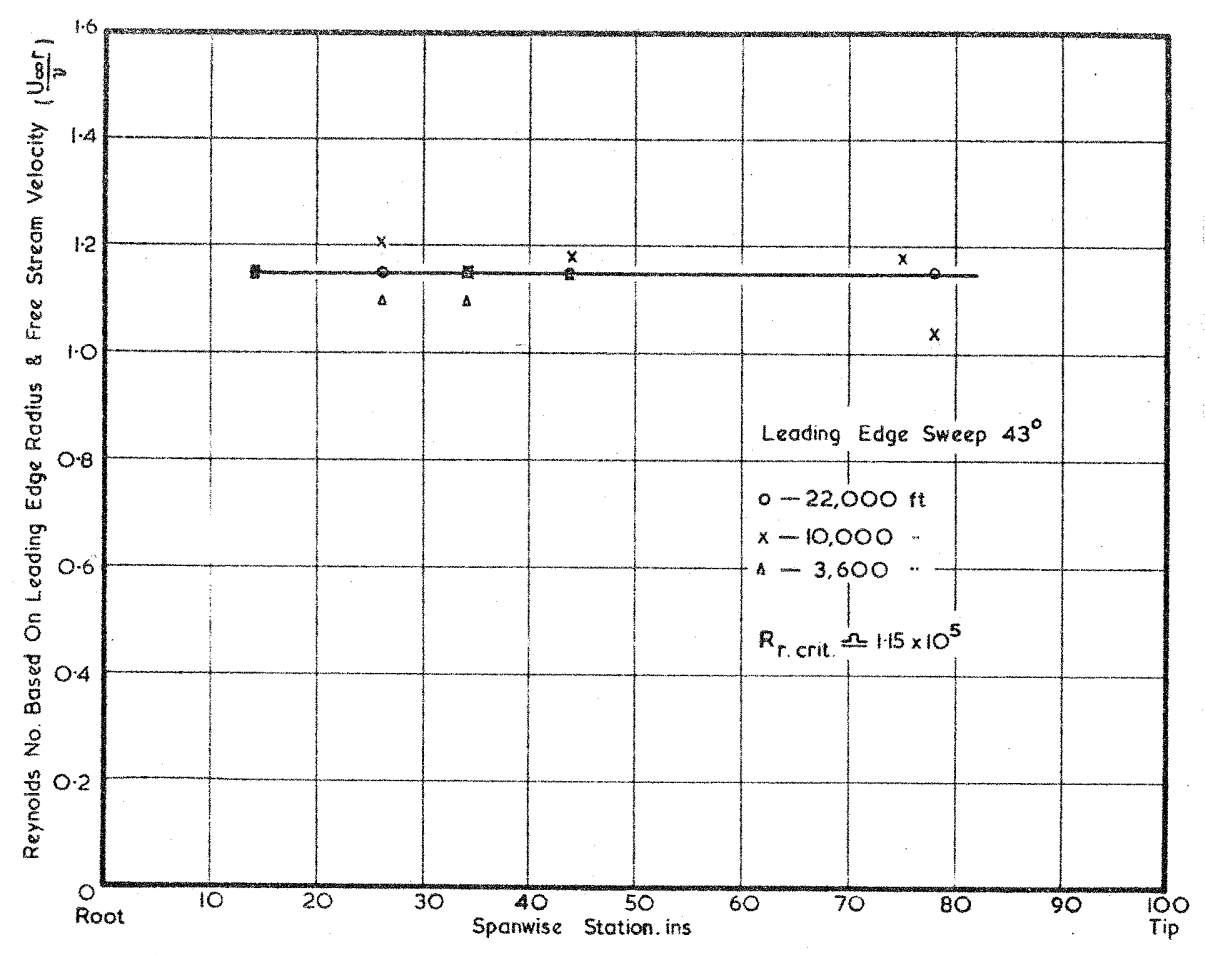

FIg. 4 CRITICAL REYNOLDS NUMBER FOUND IN FLIGHT ON THE

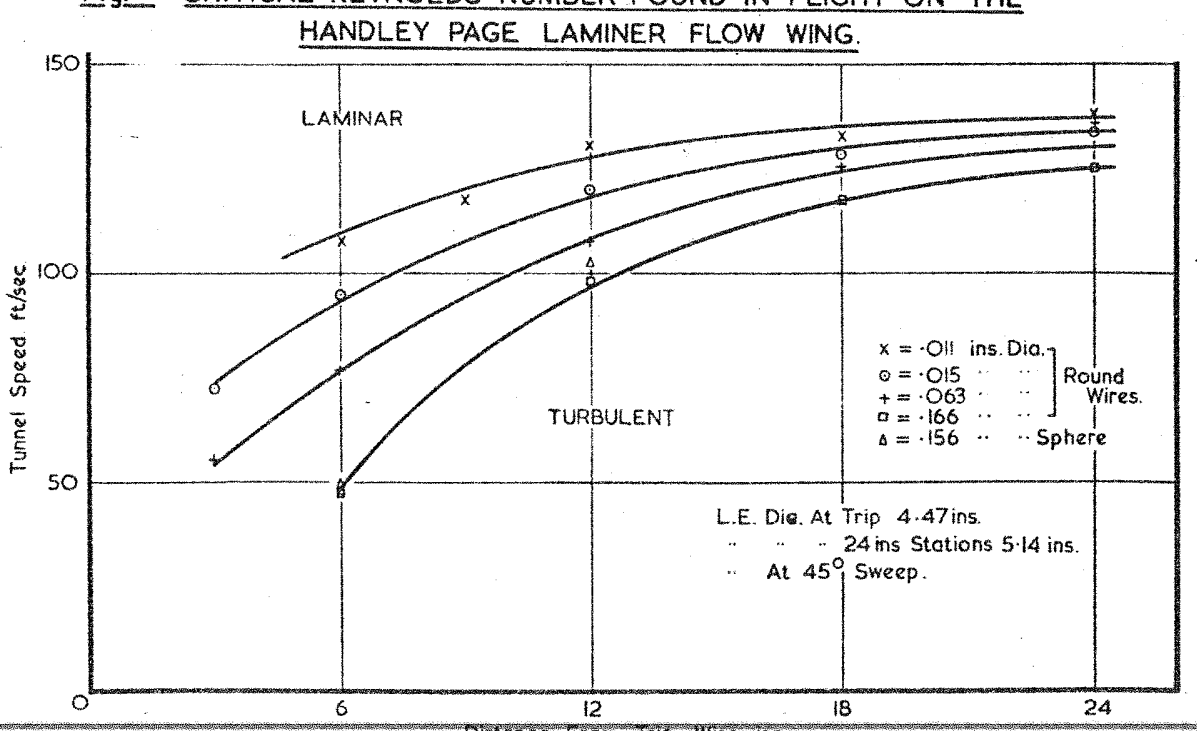

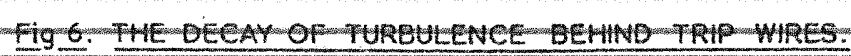

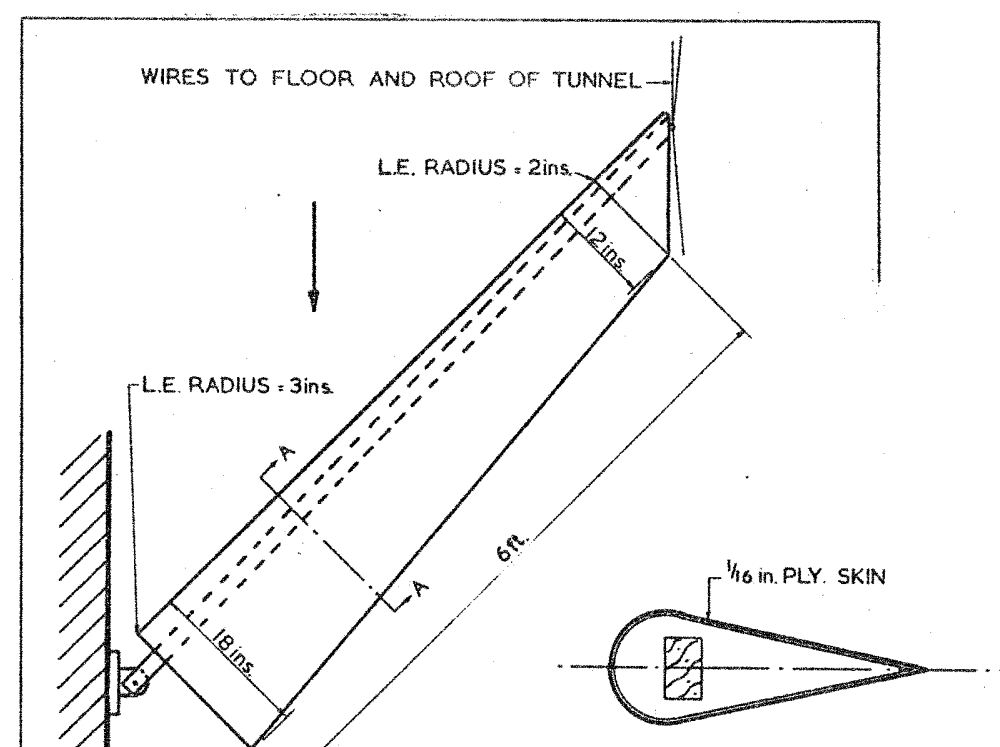

SECTION AA

Fig. 5. WIND TUNNEL MODEL

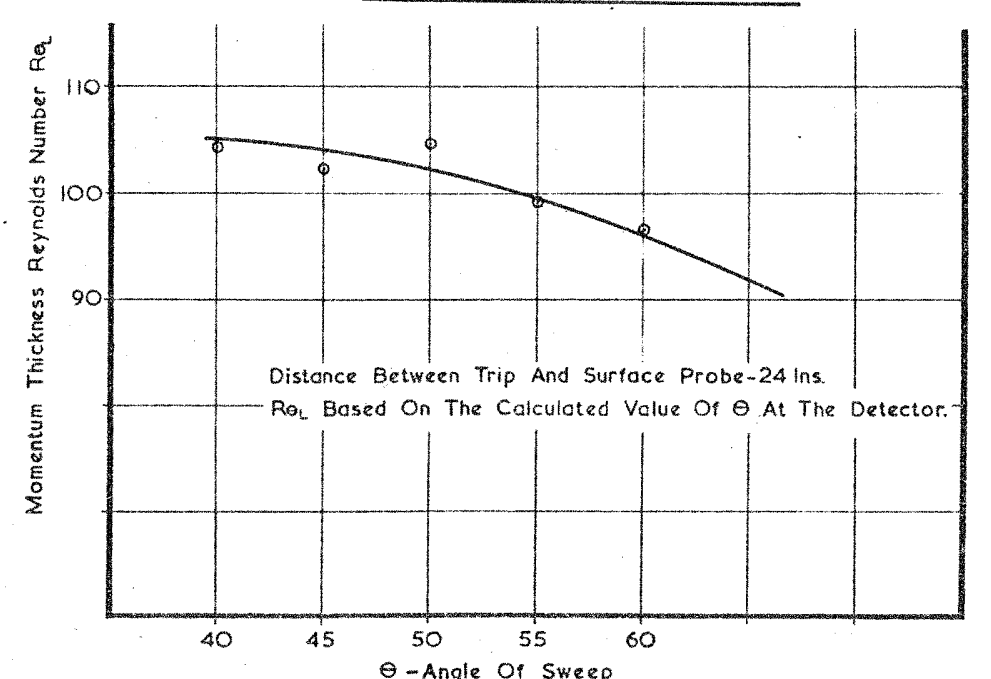

Fig. 7 CRITICAL REYNOLDS NUMBER FOR THE DECAY OF TURBULENCE 


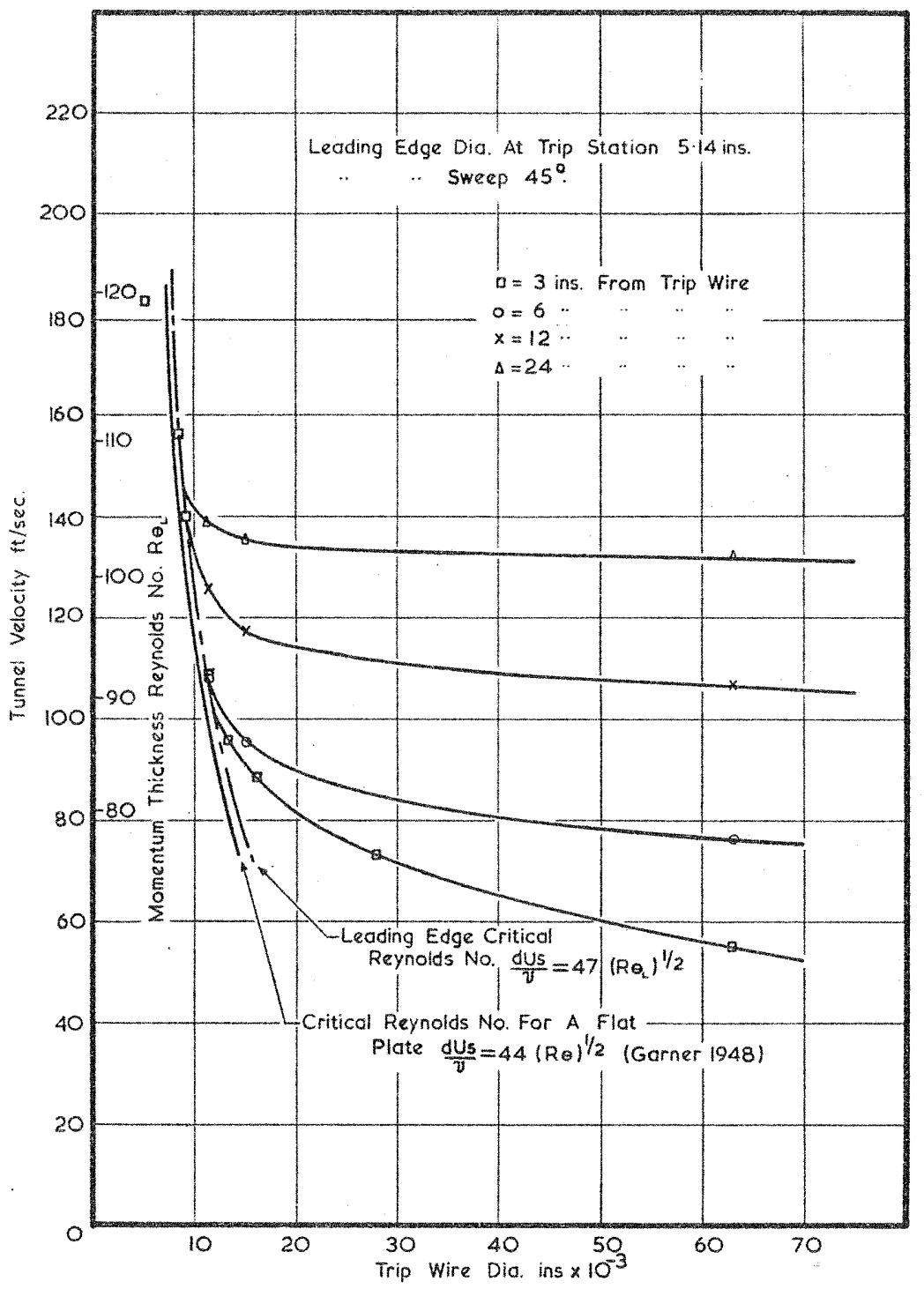

Fig 8 DETERMINATION OF CRITICAL TRIP WIRE SIZE.

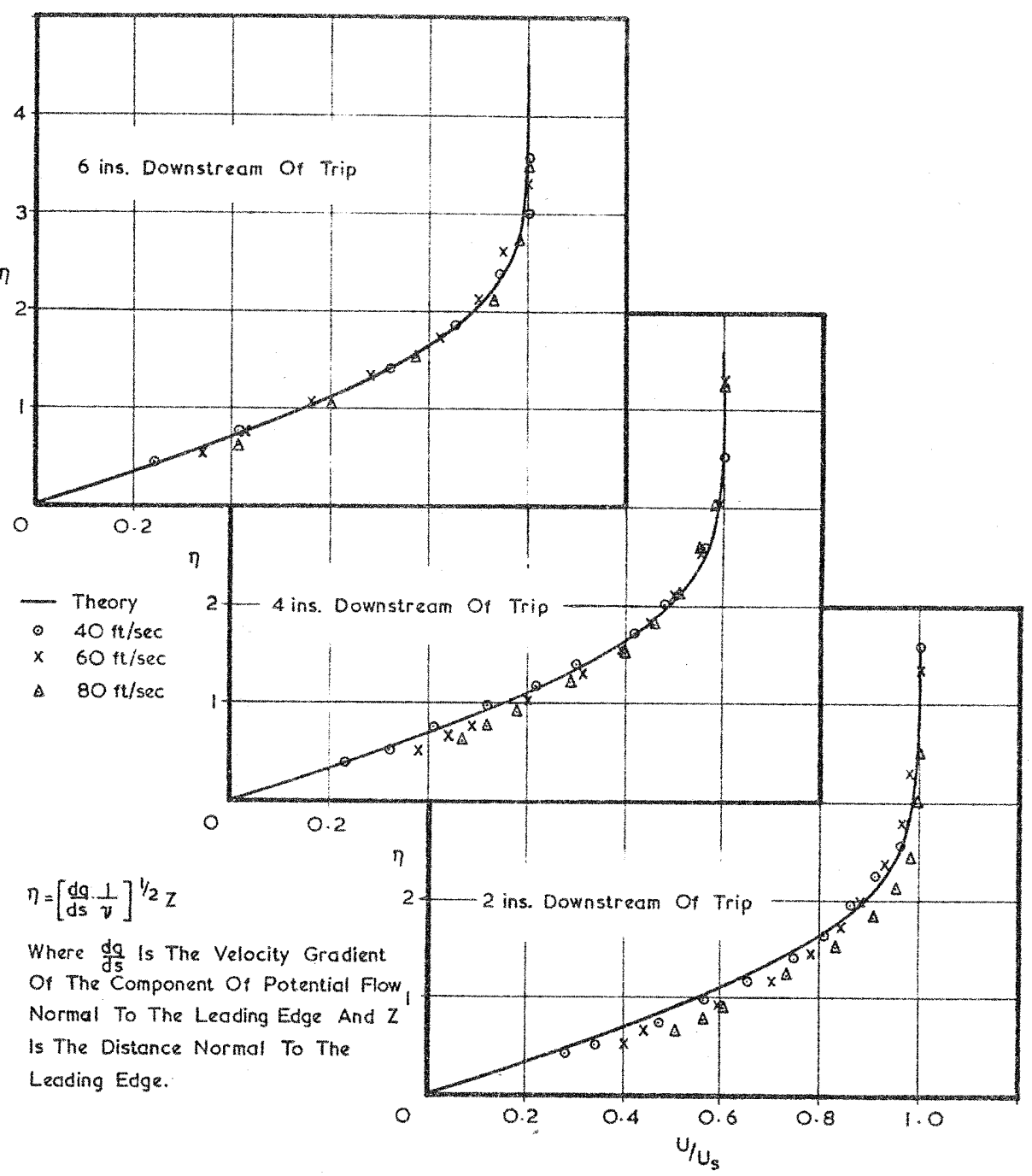

FI9.9 VELOCITY PROFILES OF THE ATTACHMENT LINE FLOW DOWNSTREAM OFA $3 / 16^{\prime}$ DIAMETER TRIP WIRE. 


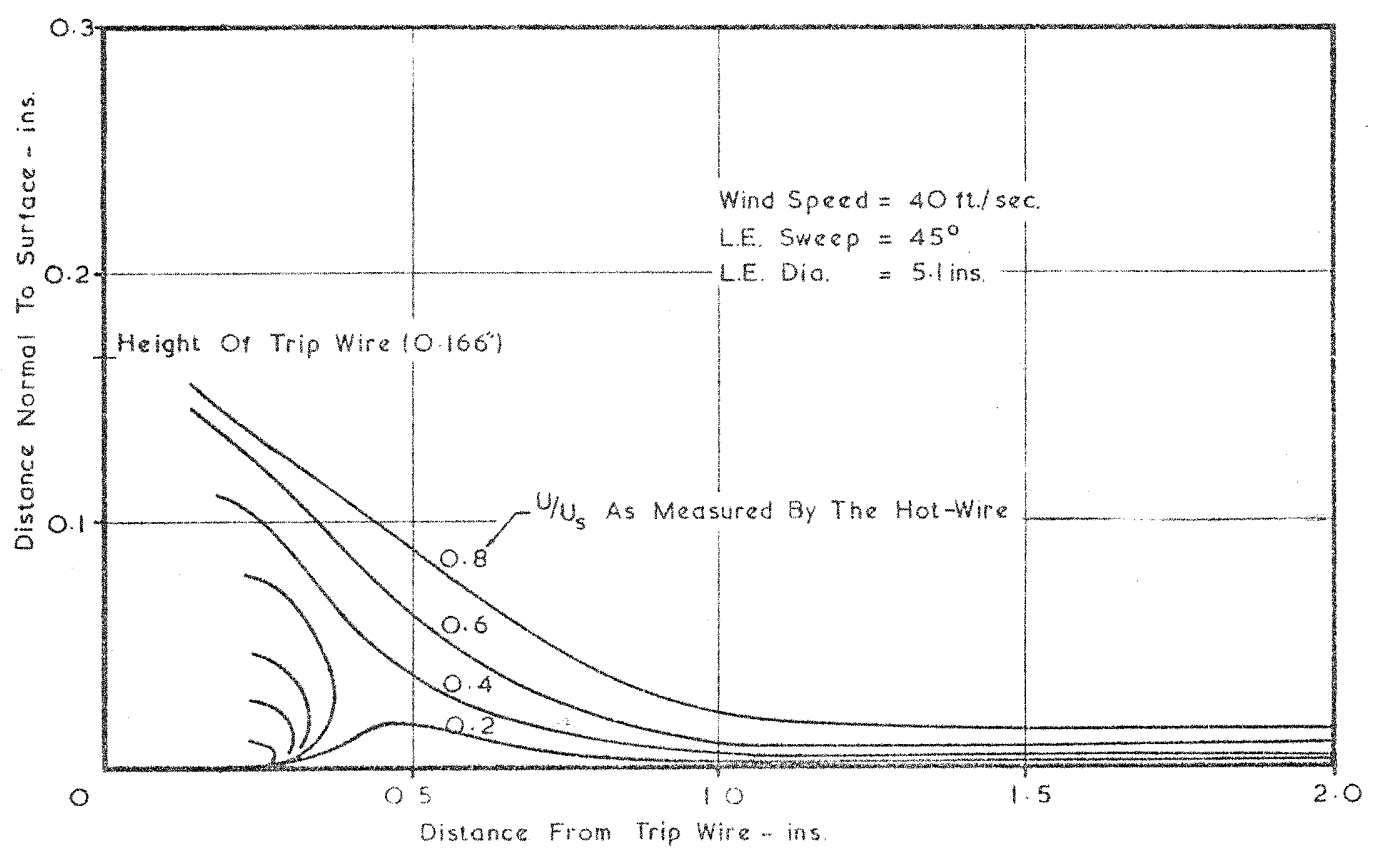

FIG.10 HOT-WIRE CONTOURS JUST OOWNSTREAM OF A 3/16INS. DIA TRIP WIRE

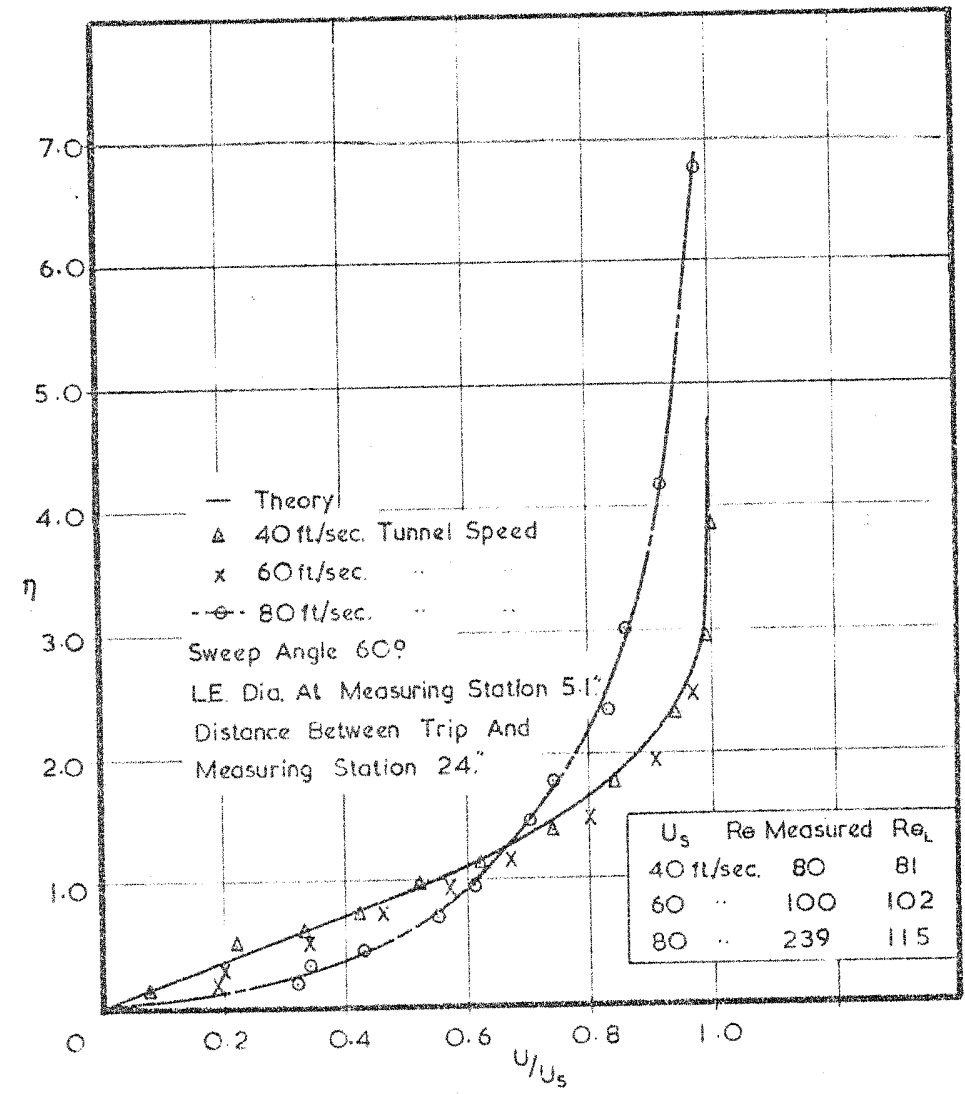

FIG.1I VELOCITY PROFILES AT VARIOUS TUNNEL SPEEDS DOWNSTAEAM OF A O.063" TRIP WIRE. 


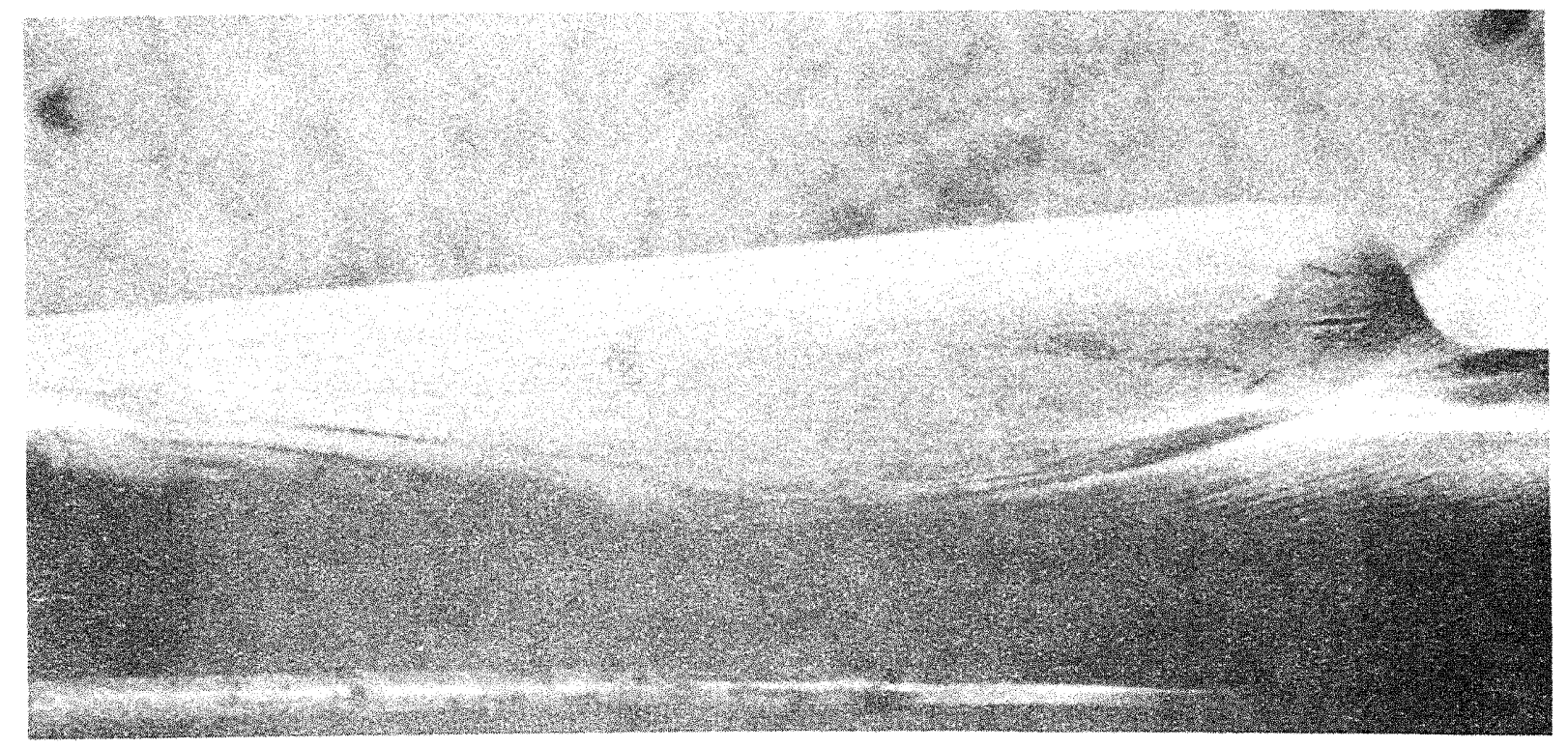

FIG. 12 SIDE VIEW OF PLASTICINE BUMP ON TTHE WIND TUNNEL MODEL

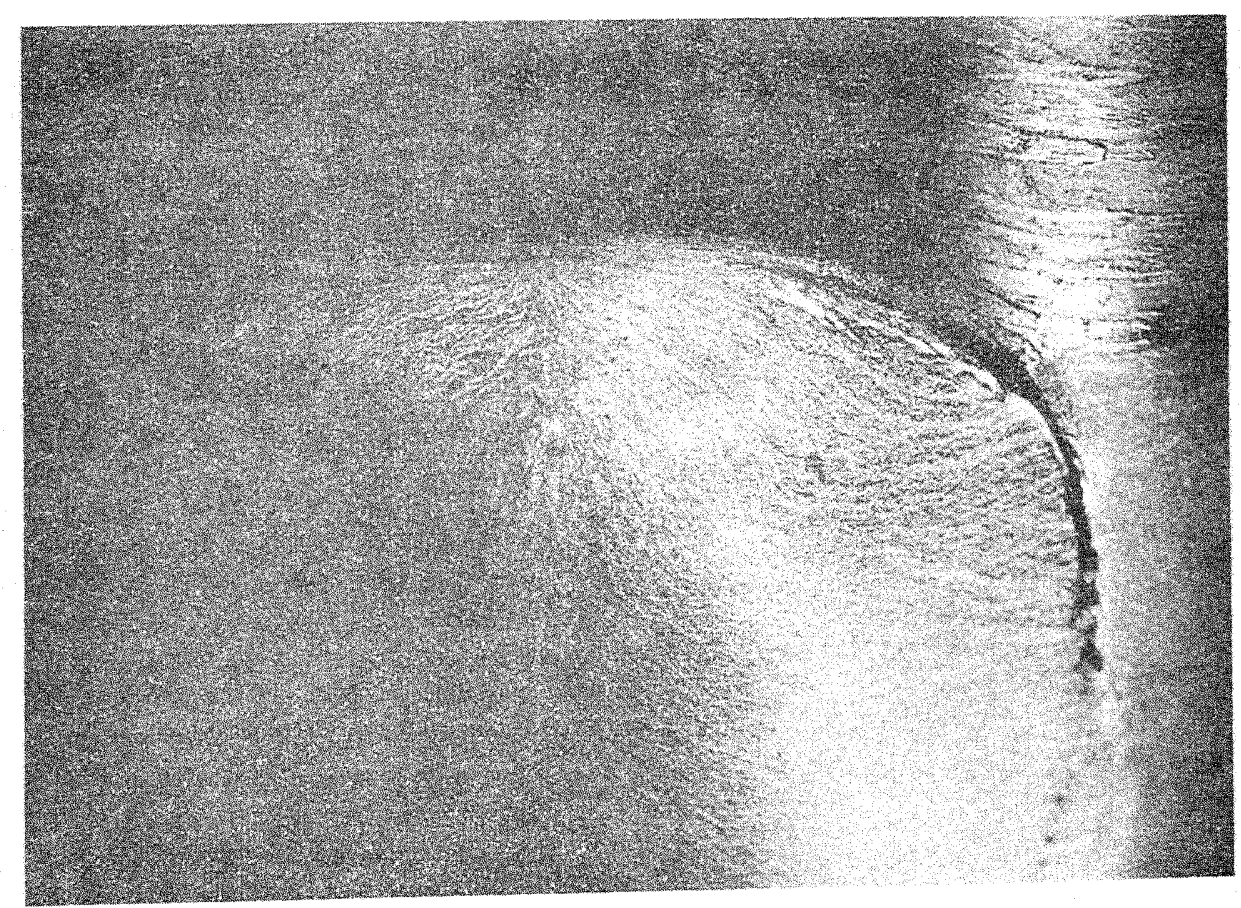

FIG. 13 FRONT VIEW OF BUMP WITH LAMP-BLACK FLOW LINES SHOWING A STAGNATION REGION. 


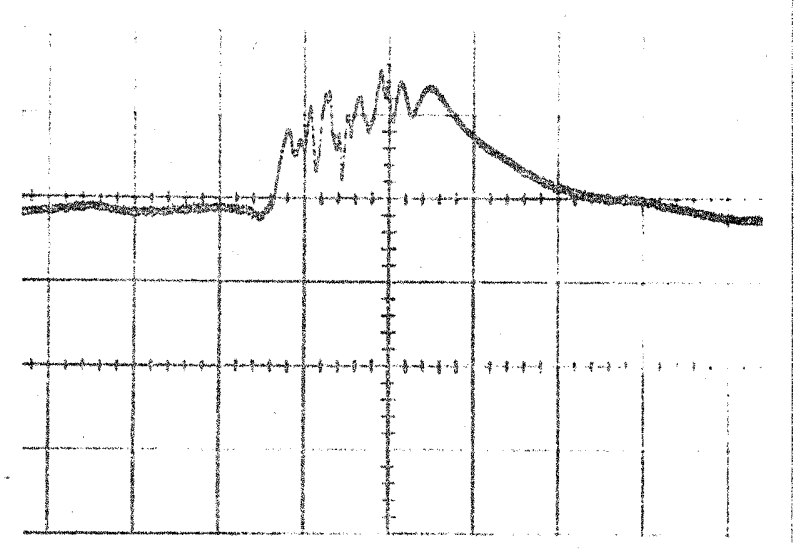

NO FHER. SIGNAL SHOWS A TAL AT THE TRAMUG EOGE.

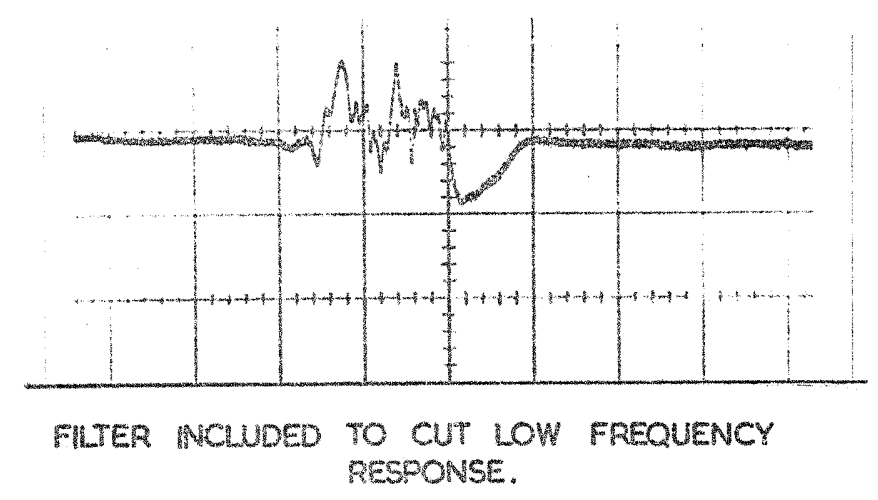

$60^{\circ}$ LEADING EDGE SWEEP. HOT FILM GAUGE PTTED I2NS FROM SPARK. TUNNEL SPEED BOFI/SEC. 10.5MS. DELAY AND 2MS/CM. SWEEP SPEED.

FIG.14. HOT-FILM RECORDS OF TURBULEN SPOTS TRAVELLNG ALONG THE ATTACHMENT LINE.
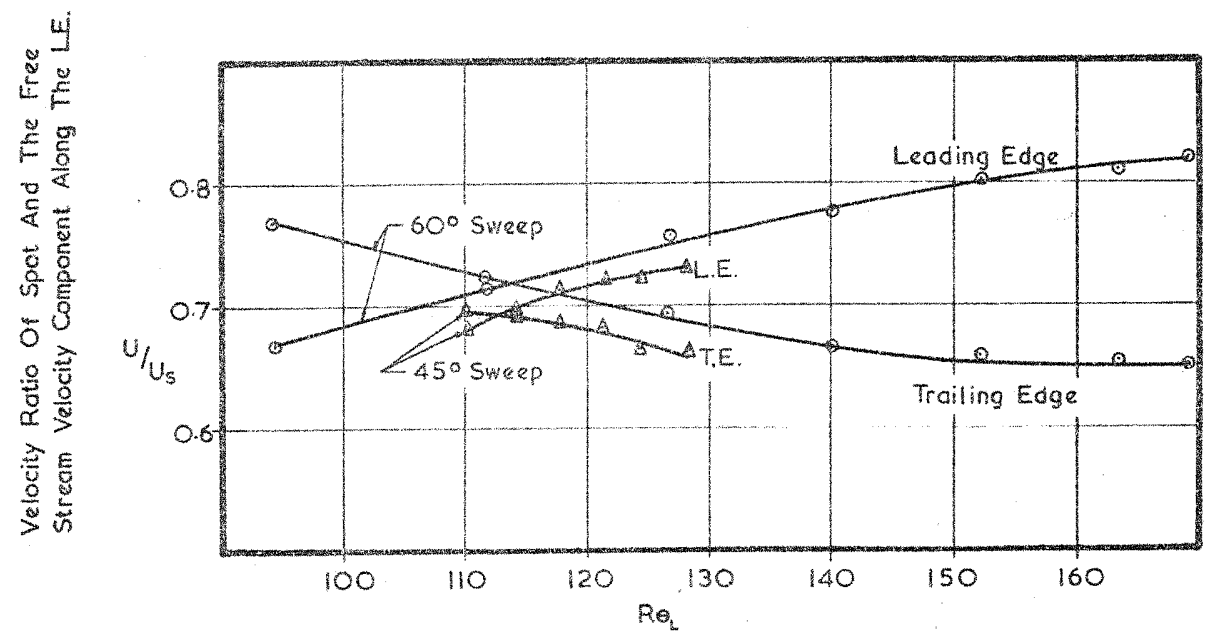

FIg. IS PROPAGATION VELOCTIES OF THE LEADING AND TRAILING EDGES OF ARTIFICIALLY GENERATED TURSULENT SPOTS. 


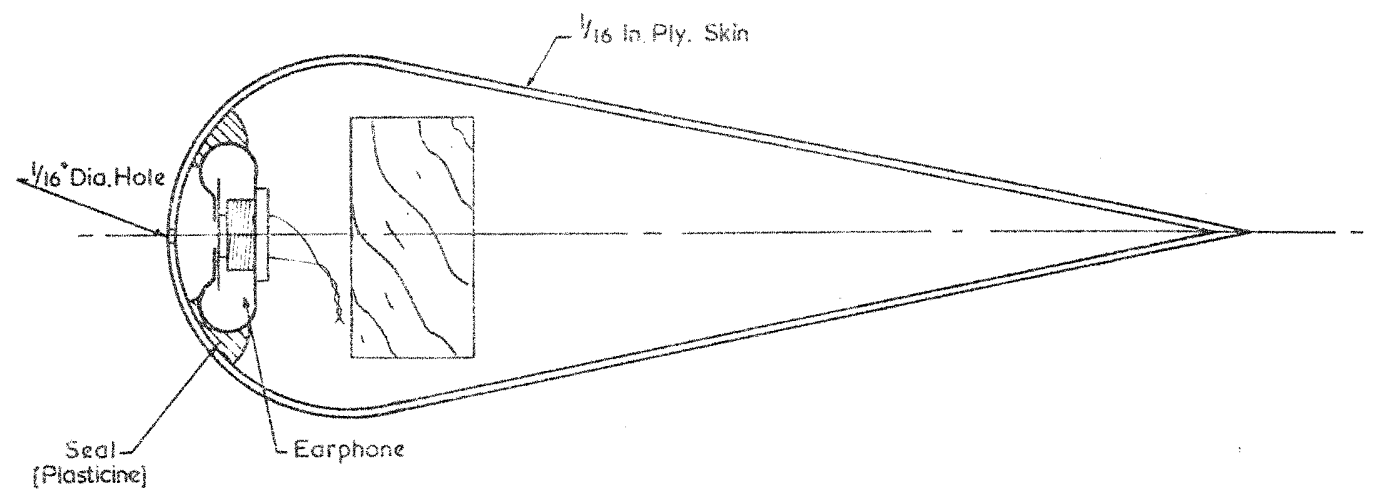

FIg. I6 DIAGRAMMATIC VIEW OF EARPHONE INSTALLATION

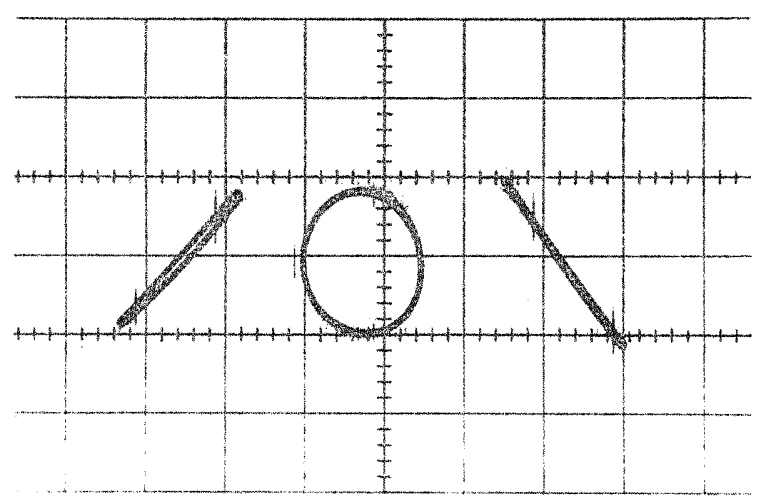

FIG.17.LISSAMON FIGURES FORMED WITH THE OSCILLATOR ANO THE HOT-FILM OUTPUT AT DIFFERENT DISTANCES FROM THE SOURCE.

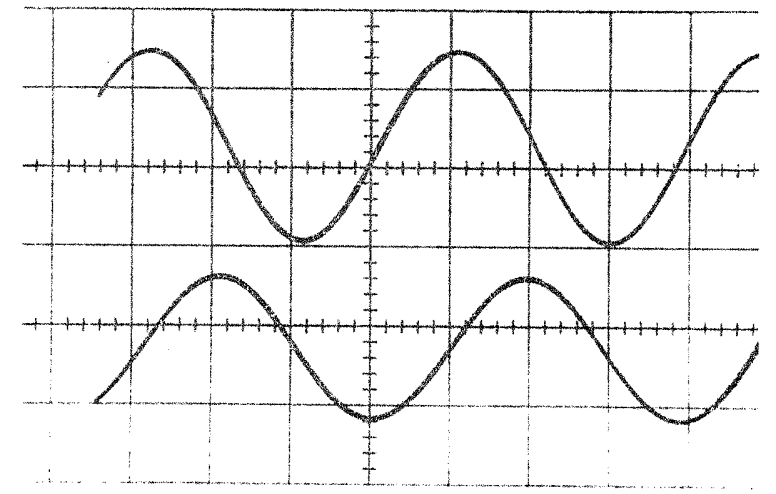

FIGI6. UPPER TRACE IS THE HOT FILM SIGNAL. LOWER . . . . OSCILLATOR OUTPUT. 


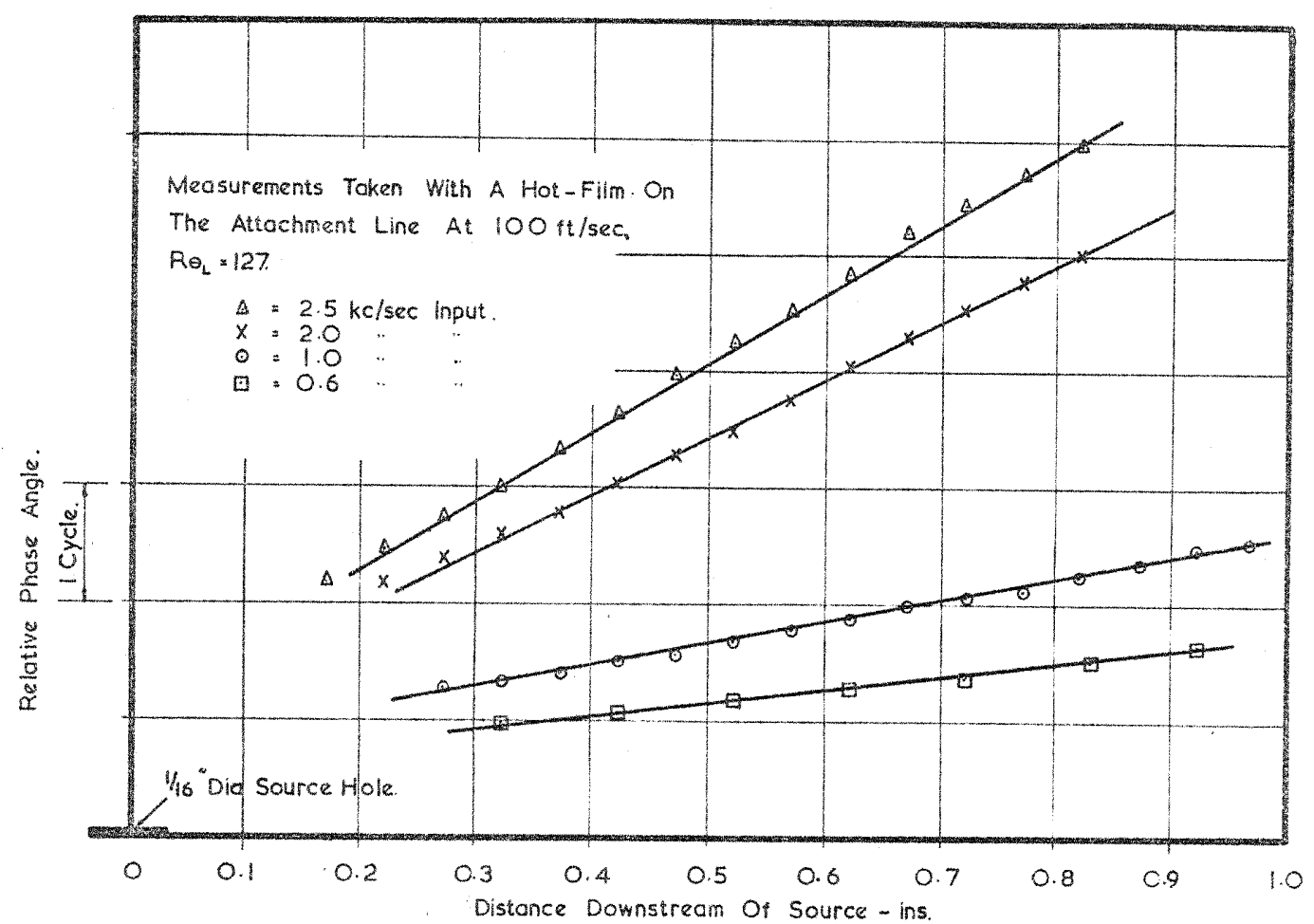

FIg.19 RELATIVE PHASE OF FORCED WAVES ALONG THE ATTACHMENT LINE.

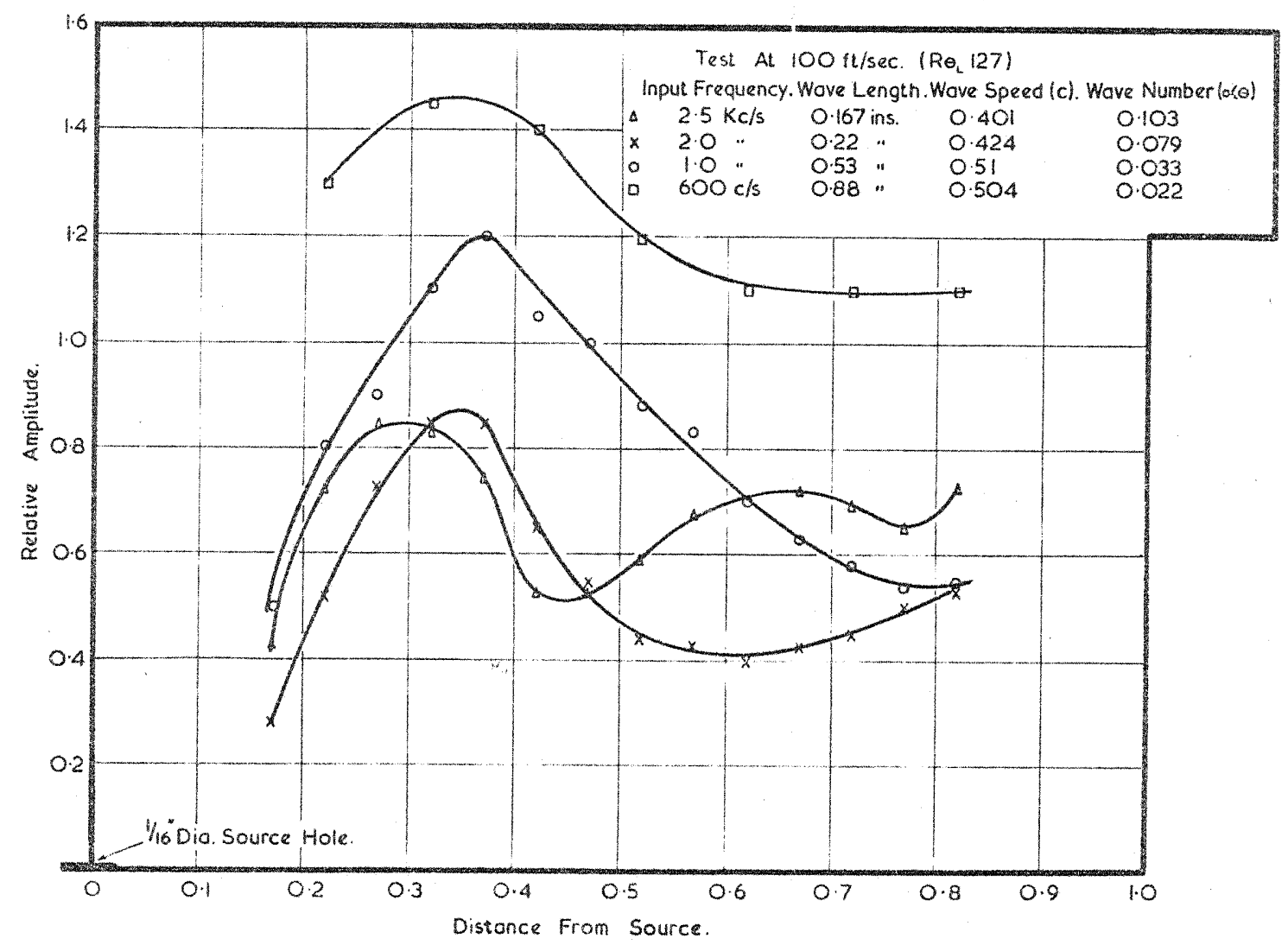

FIg 20 AMPLITUDE DISTRIBUTION OF FORCED WAVES ALONG THE ATTACHMENT LINE. 